\section{THU0016 SIALIC ACID, INTERCELLULAR ADHESION MOLECULE-1 AND RHEUMATOID ARTHRITIS: A STUDY ON THE ERYTHROCYTE MEMBRANE}

${ }^{1} S$ Cogalgil, ${ }^{2} \mathrm{~F}$ Akcay, 'S Karatay. 'Physical Therapy and Rehabilitation; ${ }^{2}$ Biochemistry, Arastirma Hospital, Erzurum, Turkey

10.1136/annrheumdis-2001.525

\section{Background}

Objectives We aimed to measure serum levels of soluble intercellular adhesion molecule-1 (sICAM-1) and erythrocyte membrane sialic acid (SA) activity and the correlation of these parameters in patients with rheumatoid arthritis (RA), and to investigate the correlation of these parameters with the disease activity.

Methods Serum sICAM-1 levels were determined with sandwich enzime-linked immunosorbent assay (ELISA) and SA concentration was determined according to the method of Shamberger in sera from 42 patients with RA and in 30 healthy controls. Erythtrocyte sedimentation rate (ESR) was determined according to the Westhergen method and C-reactive protein (CRP) by nephelometric method. Disease activity was assessed by disease activity criterias.

Results Significantly lower erythrocyte membrane SA and higher serum levels of sICAM-1 were found in patients with RA than in healthy controls ( $p<0.001$ for both). Significant negative correlation between sICAM-1 level and erythyrocyte membrane SA concentration $(\mathrm{r}=? 0.49, \mathrm{p}<0.001)$, and positive correlation between sICAM level with Ritche articular index (RAI) score and CRP ( $\mathrm{r}=0.32, \mathrm{p}<0.05 ; \mathrm{r}=0.44, \mathrm{p}<0.01$, respectively), were observed. No significant correlation was found between sICAM-1 level with ESR, age and disease duration. There was not any correlation between values of CRP, RAI score and ESR with erythrocyte membrane SA concentration.

Conclusion From these data, it is concluded that decreases in erythrocyte membrane SA concentration and increases in sICAM-1, ESR and CRP levels are present in RA, and that the decrease in erythrocyte membrane SA concentration in RA might be due to increased sICAM-1, and increased levels of sICAM-1 and correlations with other parameters may be a significant and novel marker for evaluating the disease status and the activity of RA.

\section{THU0017 CHLOROQUINE RESISTANCE IN HUMAN CEM (T) CELLS IS MEDIATED BY MULTIDRUG RESISTANCE PROTEIN 1}

${ }^{1} \mathrm{G}$ Jansen, ${ }^{2} \mathrm{RJ}$ Scheper, ${ }^{1} \mathrm{~B}$ Dijkmans. ${ }^{1}$ Rheumatology; ${ }^{2}$ Pathology, University Hospital Vrije Universiteit, Amsterdam, Netherlands

\subsection{6/annrheumdis-2001.526}

Background Drug resistance may play a role in the lack of efficacy of Disease Modifying Anti Rheumatic Drugs (DMARDs).

Objectives (1) Delineate mechanism of drug resistance to chloroquine (CHQ) and (2) does CHQ resistance confer resistance to other DMARDs.

Methods Human CEM (T) cells were made resistant to CHQ following a 4 months in vitro exposure to stepwise increasing extracellular CHQ concentrations.

Results CHQ resistant CEM cells (CEM/CHQ) displayed 3.3fold resistance to CHQ compared to CEM cells $\left(\mathrm{IC}_{50}: 129 \mu \mathrm{M}\right.$ vs $39 \mu \mathrm{M}$, respectively, following $72 \mathrm{~h}$ drug exposure). The resistant phenotype was stable for at least one month when CEM/CHQ cells were grown in the absence of CHQ. CEM/ CHQ cells exhibited full sensitivity to methotrexate (MTX) and were even collaterally sensitive $(1.7$-fold) to sulfasalazine. Interestingly, CEM/CHQ cells displayed cross-resistance to doxorubicin and daunorubicin, suggesting that multidrug resistance proteins play a role in the resistant phenotype. In fact, immunological detection (Western blots) revealed a markedly increased expression of multidrug resistance protein 1 (MRP1) in CEM/ CHQ cells compared to CEM cells. Involvement of MRP1 in CHQ resistance was further illustrated by observations that inhibitors of MRP1, probenecid and MK571, were able to reverse CHQ resistance in CEM/CHQ cells. Beyond MRP1, we noted that also cells transfected with MRP2 and MRP3 displayed resistance to CHQ (2.1- and 1.8-fold, respectively).

Conclusion Overexpression of multidrug resistance proteins (MRP1, MRP2 and MRP3) can confer in vitro resistance to CHQ and should be considered as a mechanism of lack of drug efficacy in a clinical setting.

\section{THU0018 DIFFERENTIAL CHLOROQUINE SENSITIVITY OF HUMAN CEM (T) CELLS WITH VARIOUS MECHANISMS OF RESISTANCE TO METHOTREXATE}

${ }^{1} \mathrm{G}$ Jansen, ${ }^{2} \mathrm{RJ}$ Scheper, ${ }^{1} \mathrm{~B}$ Dijkmans. ${ }^{1}$ Rheumatology; ${ }^{2}$ Pathology, University Hospital Vrije Universiteit, Amsterdam, The Netherlands

\subsection{6/annrheumdis-2001.527}

Background Methotrexate (MTX) is the anchor drug in rheumatoid arthritis treatment, either as monotherapy or in combination with other antirheumatics, e.g. chloroquine (CHQ).

Objectives Does resistance to MTX influence sensitivity to $\mathrm{CHQ}$, and if so, by what mechanism?

Methods In vitro CHQ sensitivity was evaluated in human CEM (T) cell lines, wild type CEM $\left(\mathrm{CEM}^{\mathrm{wt}}\right)$ and 3 CEM sublines resistant to MTX due to reduced cellular uptake (CEM/MTXtransport $^{\text {low }}$ ), elevated levels of dihydrofolate reductase (CEM/ MTX-DHFR ${ }^{\text {up }}$ ) or impaired polyglutamylation (CEM/MTXFPGS $^{\text {low }}$.

Results CEM/MTX-transport ${ }^{\text {low }}$ cells were 1.5 -fold more sensitive to CHQ than $\mathrm{CEM}^{\mathrm{wt}}$ cells $\left(\mathrm{IC}_{50}: 25 \mu \mathrm{M}\right.$ vs $39 \mu \mathrm{M}$, respectively, after $72 \mathrm{~h}$ drug exposure). However, CEM/MTX-DHFR ${ }^{\text {up }}$ and CEM/MTX-FPGS ${ }^{\text {low }}$ cells were 2.3 -fold $\left(\mathrm{IC}_{50}: 89 \mu \mathrm{M}\right)$ and 1.9-fold $\left(\mathrm{IC}_{50}: 74 \mu \mathrm{M}\right)$ resistant to $\mathrm{CHQ}$, respectively, compared to $\mathrm{CEM}^{\mathrm{wt}}$ cells. The mechanism of $\mathrm{CHQ}$ resistance in CEM/ MTX-DHFR $^{\text {up }}$ and CEM/MTX-FPGS ${ }^{\text {low }}$ cells is likely due to overexpression of multidrug resistance protein 1 (MRP1). This was suggested by a low level (1.5-2-fold) cross-resistance to doxorubicin and daunorubicin, and observations that an inhibitor of MRP1, MK571, was able to reverse CHQ resistance. The same phenotypic changes were noted in CEM/MTX-transport ${ }^{\text {low }}$ cells with acquired resistance to CHQ (4-fold) after in vitro exposure to stepwise increasing extracellular CHQ concentrations.

Conclusion Development of MTX resistance can be associated with up regulated expression of MRP1, which, concomitantly, can confer cross-resistance to CHQ. Analysis of MRP1 expression in inflammatory cells should therefore be considered as an important parameter determining the efficacy of anti-rheumatic (combination) therapy. 